María Marta Mariconde*, Adriana Incatasciato**

\title{
El color en la revitalización del patrimonio modesto ${ }^{1}$
}

\author{
Color in the revitalization of modest heritage \\ Cómo citar:
}

Mariconde, M. \& Incatasciato, A. (2019). El color en la revitalización del patrimonio modesto. Designia, $7(1), 9-33$

${ }^{1}$ Trabajo que se presenta como producto de Tareas de Extensión realizadas en el marco del Instituto del Color de la Facultad de Arquitectura, Urbanismo y Diseño de la Universidad Nacional de Córdoba. Las autoras son miembros integrantes (Docentes Investigadoras) de dicho espacio institucional.

* Arquitecta. Docente e investigadora Facultad de Arquitectura Urbanismo y Diseño de la Universidad Nacional de Córdoba, Argentina. Profesora Adjunta de la cátedra Morfología III y Profesora Asistente de la cátedra Teoría y Métodos B de la carrera de arquitectura.

Directora de proyectos de Investigación con subsidio de la SECyT

UNC, y del Equipo de investigación TEFU FAUD UNC, en el marco del cual se desarrolla el Proyecto Aprender a Ver, como tareas de extensión y articulación con el medio local. Miembro del Instituto del Color donde desarrolla las tareas de investigación, extensión y transferencia a la comunidad de los avances desarrollados.

E-mail: mmmconde@gmail.com ORCID: https://orcid.org/0000-0002-0253-2890

** Arquitecta. Ex Docente e investigadora Facultad de Arquitectura

Urbanismo y Diseño de la Universidad Nacional de Córdoba, Argentina. Docente retirada, cargo Profesora Adjunta de la cátedra Morfología III de la carrera de arquitectura. Directora, Co directora de proyectos de Investigación con subsidio de la SECyT UNC hasta 2017, y actualmente consultora académica del Equipo de investigación

TEFU FAUD UNC, en el marco del cual se desarrolla el Proyecto Aprender a Ver, como tareas de extensión y articulación con el medio local. Miembro del Instituto del Color donde desarrolla las tareas de investigación, extensión y transferencia a la comunidad de los avances desarrollados. E-mail: adrincat@gmail.com ORCID: https://orcid.org/0000-0002-6908-8552
Palabras clave:

Color urbano, patrimonio,

revitalización, pertenencia, identidad.

Key words:

Urban color, heritage,

revitalization, belonging, identity.

Recibido: 31/08/2018

Aceptado: 6/09/2019 


\section{Resumen:}

Los cambios culturales contemporáneos invaden los sentimientos de pertenencia y el desarrollo del sentido de lugar, como una necesidad del hombre de identidad con su ciudad. El lugar está ligado a la identidad. Cada grupo humano sostiene una relación muy estrecha con su lugar, con su territorio, ejerce una apropiación del mismo, posee un sentimiento de pertenencia y de orientación en él.

Ese sentimiento de "pertenecer a" implica compartir intereses, memorias y experiencias con otros; poseer valores en común y sentimientos profundos de identificación, además de situarse en un territorio compartido. Al respecto, según Marina Waisman, el concepto de identidad implica el de unidad, adquiriendo sentido si está en presencia de una multiplicidad que le es ajena. Así pues, la identidad de un grupo humano se va construyendo al tiempo que va calificando el propio entorno.

El enfoque sobre la imagen morfológica expresiva deviene en uno de los instrumentos de lectura del desarrollo urbano para todas aquellas intervenciones que alteran la consolidación del tejido. Desde esta mirada, el color, como atributo ligado a la forma, debe ser considerado un importante recurso en la estructuración de la imagen, conformándose en un referente del entorno. El color verifica y sustenta su actuación, construye, acentúa o materializa la imagen, logrando ser referente identificatorio, de apropiación y arraigo del ciudadano. En este sentido es considerado como una de las herramientas más fuertes, tanto eficaces cuanto económicas, para la revalorización y puesta en valor de micro-áreas con valor de patrimonio modesto, en un corto plazo.

Para la recuperación del imaginario cultural de una región se debe trabajar entonces en la consolidación y recuperación de la identidad, logrando la puesta en valor del patrimonio vivo, arquitectónico y social. En ese sentido, se presentarán propuestas de intervenciones cromáticas realizadas en localidades del interior de la provincia de Córdoba, Argentina. 


\section{Abstract:}

Contemporary cultural changes invade the feelings of belonging, and the development of the sense of place as a need of the man's identity with his city. The place is linked to identity. Each human group maintains a very close relationship with its place, with its territory, exerts an appropriation of it, possesses a feeling of belonging and orientation in it.

That feeling of "belonging to" implies sharing interests, memories and experiences with others; to have common values and deep feelings of identification, in addition to being in a shared territory. In this regard, according to Marina Waisman, the concept of identity implies that of unity, acquiring meaning if it is in the presence of a multiplicity that is alien to it. Thus, the identity of a human group is being built while qualifying the environment itself.

The focus on the expressive morphological image becomes one of the instruments for reading urban development for all those interventions that alter tissue consolidation. From this perspective, color, as an attribute of form, must be considered an important resource in the structuring of the image, conforming to a reference of the environment. The color verifies and sustains its performance, builds, accentuates or materializes the image, managing to be an identifying reference, of appropriation and rootedness of the citizen. In this sense, it is considered as one of the strongest tools, both effective and economic, for the revaluation and enhancement of micro-areas with a modest heritage value, in a short term.

For the reactivation and recovery of the cultural imaginary of a region, it is necessary to work on the consolidation and recovery of the identity, achieving the enhancement of the living, architectural and social heritage. Chromatic interventions will be presented, in that sense, in localities of the Province of Córdoba, Argentina. 


\section{INTRODUCCIÓN}

En los escenarios urbanos actuales, el proceso de globalización produjo la actualización, modernización y transformación de la ciudad, provocando fuertes rupturas con el pasado y la identidad de la cultura local, alterando el contexto ambiental e incrementando el impacto del hábitat construido (De Schiller, 2001). En los países latinoamericanos, y en Argentina en particular, de marcada población de inmigrantes, se manifiesta una dinámica de fragmentación social que a la vez es cultural. Nuestra cultura es una cultura de fragmentos, trasladada a su vez, como tal, a la imagen de la ciudad, de perfiles y formas heterogéneas, donde tiempo y espacio adquieren otras dimensiones, como testigos de múltiples y diversas relaciones. La imagen urbana es la síntesis de la relación entre las identidades culturales y espaciales.

La habitual percepción y experiencia del espacio urbano es reemplazada por nuevas vivencias relacionadas con lo virtual, el uso de las tecnologías emergentes, tabletas digitales, teléfonos inteligentes, lo mediático, que genera nuevas maneras de comunicación.

Estos cambios culturales invaden los sentimientos de pertenencia y el desarrollo del sentido de lugar, como una necesidad innata del hombre de habitar, de identificarse con su lugar, ciudad o territorio, en busca de desarrollarse a través de estructuras raigales.

El sentimiento del hombre de sostener una relación tan estrecha con su lugar, de "pertenecer a", de arraigo, está ligado a las formas de convivencia, al modo de vida de cada grupo humano en particular. Además de situarse en un territorio físico compartido, implica también compartir con los otros, intereses, memorias y experiencias; poseer normas y valores en común y sentimientos profundos de identificación. El hombre ejerce así una apropiación del territorio, posee un sentimiento de pertenencia y de orientación en él. Se identifica crítica y creativamente con el marco normativo axiológico del mundo espacial-socio-cultural que lo conforma y que a la vez él ayuda a conformar (Del Acebo Ibáñez, 1996, p. 200).

La reflexión de la arquitecta cordobesa Marina Waisman aporta que el concepto de identidad implica el de unidad, el cual adquiere sentido si está en presencia de una multiplicidad que le es ajena.

La identidad presupone vivencias en un determinado tiempo histórico; la identidad de un pueblo es consecuencia de su historicidad, de la tradición, de lo que se arrastra del pasado, de lo que en él permanece a través del tiempo, de lo que se trae de generación en generación; es decir, es lo consagrado por la comunidad. 
Forman parte de esta identidad, en el plano arquitectónico, las distintas formas de apropiación y usos de los espacios urbanos, las formas de construirlos e incluso de valorarlos. Pero también hay una construcción permanente de la identidad urbana que acepta e incorpora nuevas propuestas, nuevas intervenciones, a través del devenir histórico.

En esta línea de pensamiento, el patrimonio es expresión de la cultura y la identidad de un pueblo; se trata de una trama compleja, constituida por bienes tangibles, naturales o construidos, y bienes intangibles pertenecientes a una comunidad.

A pesar de la complejidad, y en la contradicción, es necesario establecer una comunicación de equilibrio del hombre con su territorio, de tipo social, cultural, histórico, simbólico, identitario, de valoración del paisaje y el ambiente, y también como recurso económico determinado por el valor del mercado. Esto lo compromete con un paisaje sustentable, y la posibilidad de construir una imagen de ciudad singular e irrepetible, un reconocimiento colectivo desde el cual se reproduzca el sentido de pertenencia de una comunidad definiendo su dimensión simbólica. Al habitar, el hombre abreva y se nutre en un espacio de sentido. Habitar supone habitar-se, inteligirse como propio objeto de conocimiento y de realización como realidad y como proyecto único e irrepetible. (Del Acebo Ibáñez, 1996, p. 202)

Es por ello imperioso plantear estrategias para proteger, gestionar y planificar el habitar del hombre, teniendo siempre presente que toda degradación del territorio incluye tanto la degradación del medio ambiente como la del patrimonio construido y del sistema social. 
Una de las estrategias factibles para proteger, gestionar y planificar el habitar del hombre es enfocarse en el conjunto de aspectos morfológicos modélicos, con expresión figurativa y significados particulares, de aquellas intervenciones urbanas existentes que alteran la consolidación del tejido.

Es significativo que la mirada morfológica no se circunscriba solo a los componentes geométricos y estructurales. La apariencia formal y expresiva, entendida a partir de la geometría, el color, las texturas y cesías, refuerza la configuración del lenguaje urbano junto a otros componentes como el mobiliario urbano, la publicidad y la vegetación.

Distintas micro-áreas urbanas, con valores morfológicos significativos, con preexistencias y legados patrimoniales, o con potencialidades paisajístico-ambientales actualmente desvalorizadas, debieran ser rescatadas e incorporadas al espacio público, considerándose esto como una importante acción de revalorización de la imagen en la construcción de la ciudad.

En este contexto, muchos municipios se concientizan en la idea de proponer acciones posibles para mantener, recuperar, potenciar, revalorizar y consolidar áreas urbanas. Corresponde el que sean planteadas holísticamente desde la gestión pública, a través de distintos instrumentos urbanísticos de ordenamiento normativo. Deben apuntar primeramente a la identificación de aquellas alteraciones locales a las que el medio es sensible, de modo que al neutralizarlas se eviten posibles riesgos de distorsión, alteración o desaparición de los sitios con valores naturales, arquitectónicos y urbanos singulares. Esto permitirá incrementar la competitividad de una población o región, potenciando sus valores particulares.

La estrategia debe ser proyectada con objetivos básicos y principios orientadores ponderados, destacándose la participación ciudadana, la educación y la investigación, la coordinación entre los sectores o actores intervinientes, la prevención y el manejo sustentable en el tiempo.

Pero se entiende que ese rescate o puesta en valor de la ciudad no significa entregarse a una modernidad global, sino buscar las esencias de una imagen específica, local, que logre paulatinamente el valor de obra universal a partir de su síntesis entre modernidad, cultura del lugar y la interpretación del genius loci, conquistando un paisaje caracterizado con una identidad única.

Ciertas áreas paradigmáticas de localidades de pequeña y mediana densidad expresan debilidad en la calidad de su imagen urbana, aunque con la interesante presencia de sectores definidos de patrimonio modesto. 
El concepto de "patrimonio modesto" es trabajado dentro del contexto latinoamericano a partir de los aportes de Marina Waisman, desde Córdoba, entendiéndolo como la valorización de todo aquel:

\section{... tejido urbano y en los tipos arquitectónicos que expresan formas de la vida social, en los edificios que representan un hito importante en la memoria social, en ciertas imágenes urbanas en las que la composición de las fachadas desempeña un papel fundamental, y en las atmósferas creadas por un modo de ocupación de los sitios o de la utilización de la vegetación. (Waisman, 1989, p. 32)}

De esta manera, lo define como la extensión de este concepto a las modestas construcciones que constituyen, por ejemplo, un tejido urbano. En sus textos también rescata un valor muy importante, que es el del tipo arquitectónico, el cual expresa no solo los modos de vida referidos al uso de cada edificio, sino también los relacionados con la vida urbana y social, es decir que caracterizan una forma urbana particular. Interesa en este aspecto rescatar lo explicado por el arquitecto Francisco Griotto $^{2}$ en su interesante Proyecto PAMA (Patrimonio Arquitectónico Modesto Argentino), Plataforma Interactiva Comunitaria, de trabajos acerca del patrimonio modesto argentino, donde presenta una aproximación más actual hacia el patrimonio modesto, según los estudios de Sánchez y Cuezzo:

\section{... conjunto de aquellos bienes urbanos característicos de cada ciudad, principalmente las viviendas de pequeña y mediana escala que constituyen tejidos concentrados y/o dispersos, destinados a clases sociales medias y realizados por constructores, idóneos y en menor medida profesionales, utilizando técnicas y tecnologías principalmente postindustriales. (Sánchez y Cuezzo, 2012, p. 266)}

\footnotetext{
${ }^{2}$ Trabajo del Arq. Francisco Griotto como becario. Tema: Proyecto PAMA (Patrimonio Arquitectónico Modesto Argentino) Plataforma Interactiva Comunitaria. Programa de Becas de Innovación Tecnológica Socio-productiva (BITS) SEU SECyT de la UNC. Directora: Arq. Mgtr. María Rebeca Medina. 2017-2018
}

Es así que, desde la morfología urbana, se destacan en esos casos tipologías edilicias concretas, que tienen un valor patrimonial en relación con su doble escala de acción: la de las construcciones en sí mismas y la de los paisajes urbanos que estas componen. Establecen un diálogo entre el presente y el pasado con una apariencia formal y una expresión de la vida social. Se convierten en únicas, memorables, con identidad e inserción en el marco local y regional, y con significación como conjunto urbano.

Re-categorizar y re-valorizar el pasado le da sentido al presente; el patrimonio modesto considera aquellas huellas que nos traen "solamente la memoria de la gente común" (Waisman, 1995, p. 73). Ante la perspectiva de debilidad o dificultad en las lecturas de las ciudades, cada vez más complejas, es lógico pensar que cualquier instrumento urbanístico que no asuma esta instancia seguramente fracasará. 
El color, como atributo ligado a la forma y como factor morfogenético por excelencia, debe ser considerado un importante recurso en la estructuración de la imagen urbana, conformándose en un referente del entorno. El color verifica y sustenta su actuación, construye, acentúa o materializa la imagen con tecnologías innovadoras, pudiendo ser referente identificatorio y de apropiación y arraigo del ciudadano respecto a su lugar o territorio.

En este sentido, se considera como una de las herramientas más fuertes, tanto eficaces cuanto económicas, para la revalorización y puesta en valor de micro-áreas urbanas con valor de patrimonio modesto, en un corto plazo.

De esta manera, trabajar en la puesta en valor del patrimonio vivo, arquitectónico y social permite la reactivación y recuperación del imaginario cultural de una región, logrando entonces la consolidación y recuperación de la identidad.

Cabe precisar que el arquitecto es uno de los profesionales que, junto a un equipo interdisciplinario y a través de distintas aristas, está avalado para operar en las tareas de recuperación de la identidad. El arquitecto es un intelectual, pero además es un hombre de acción, que tiene necesidad de reflexión, con tres enfoques: como profesional, ser humano y miembro de la comunidad de la que forma parte. Fundamentalmente, el arquitecto es un mediador entre el hombre y la calidad de vida.

Como arquitectas, docentes e investigadoras, pertenecientes al Instituto del Color de la Facultad de Arquitectura, Urbanismo y Diseño de la Universidad Nacional de Córdoba, el cual surge en 1996 como un ámbito de estudio para investigaciones relacionadas con la temática del color urbano, se exponen a continuación dos propuestas de intervenciones cromáticas desarrolladas en localidades serranas cercanas a la ciudad de Córdoba, Argentina.

Para contextualizar el desarrollo de las presentaciones, cabe aclarar que la Secretaría de Investigación de la FAUD-UNC es la que aglutina a los institutos, centros y talleres donde se producen, profundizan y perfeccionan los conocimientos, se organizan eventos, se asesora a los cursos académicos y se difunden y ofrecen sus saberes como apoyo a las iniciativas y necesidades individuales y regionales, prestando sus servicios a la comunidad. Coordina sus tareas con la Secretaria de Extensión, que actúa como campo de práctica y acción directa sobre el medio, y a través de la cual se concretan convenios con otras instituciones, organismos gubernamentales y no gubernamentales, empresas e iniciativas individuales, entre otros. 
Se pone así en evidencia que los tres postulados de la reforma universitaria de 1918 (la docencia, la investigación y la extensión) producen articuladamente la retroalimentación en lo que a la producción del conocimiento respecta, ya que la experiencia en la difusión y prestación de servicios se revierte en la docencia, reciclando con sus demandas la enseñanza de la arquitectura, en una orientación realista con el medio.

\section{Estrategias de acción}

Las propuestas de ambas localidades coinciden en la factibilidad de poner en valor los orígenes de la imagen urbana, de apostar a la definición identitaria de las mismas, que con el tiempo se han ido desdibujando, recuperando ciertas áreas paradigmáticas consideradas patrimonio modesto y permitiendo una lectura a futuro, legible y memorable.

Las dos poblaciones son de pequeña densidad, una en el área metropolitana de Córdoba, la ciudad de Malagueño, y la otra, la localidad de Huerta Grande, en el corredor del valle de Punilla, provincia de Córdoba.

Las propuestas de intervención que definió el equipo están dirigidas a trabajar con ciertos aspectos que tocan a la problemática ambiental local, bajo el paradigma del desarrollo sustentable. Desde esa óptica, se plantean acciones de revalorización de la imagen, interviniendo en micro-áreas urbanas que poseen valores significativos a partir de cualidades morfológico-expresivas, histórico-patrimoniales o con potencialidades paisajístico-ambientales, que debieran ser incorporadas al imaginario social de la región.

Se hace especial énfasis en el diseño cromático de ciertas fachadas de interés arquitectónico, ubicadas en puntos estratégicos de la traza, que organizan sintaxis parciales o la totalidad de una cuadra o de un recorrido, reforzando situaciones particulares, con la intención de detener deterioros o posibles alteraciones y reconstruir la memoria histórica.

En las dos propuestas de intervención se visualizó como necesaria la revalorización, como una rápida acción estratégica que permitiría desarrollar planes de inversiones en el corto y mediano plazo, movilizando ciertos recursos humanos y económicos. Esto provocaría, sin dudas, la sinergia para repensar la gestión y la planificación urbano-regional, logrando respuestas ambientalmente adecuadas, con oportunidades equitativas para la sociedad, armonizando criterios para lograr el desarrollo sustentable. Se describirán las intervenciones de diseño cromático en cuanto a cómo se gestaron y se desarrollaron las propuestas. 
Los resultados esperados, respecto a los objetivos de lograr a través del diseño cromático la revalorización de la imagen y el fortalecimiento de la identidad de sus habitantes, no pueden evaluarse, ya que solo en la localidad de Malagueño, y después de muchos años de la firma del convenio entre la Universidad y la municipalidad, se dieron pequeñas acciones para concretar la propuesta. Pero con experiencias realizadas en la trayectoria del equipo en distintas oportunidades, caso expreso, por nombrar las intervenciones más destacadas: la calle Belgrano, en el barrio Güemes de la ciudad de Córdoba (1998), y el eje de la avenida Sarmiento de la ciudad de Villa Carlos Paz (2013), podemos garantizar la revalorización del área, no solo en cuanto a la recuperación del valor morfológico de su imagen o expresión, sino con los debidos cambios de conductas y comportamientos del habitar, la aprehensión y apropiación de los lugares y la recuperación de la identidad y fortalecimiento del arraigo espacial, social y cultural del habitante.

\section{Caso Malagueño}

Pequeña localidad de 10000 habitantes, ubicada a 20 kilómetros al sudoeste de la capital provincial, en una zona geográfica de transición entre las Sierras Chicas y las Sierras Pampeanas, lo que le otorga un particular y agradable microclima.

Ofrece un paisaje agreste, matizado por sus cerros y canteras. Su suelo, a pesar de que no es óptimo para los cultivos, es rico en minerales, lo que lo hace apto para el desarrollo fabril de la zona. La ciudad forma parte de un conjunto de localidades "caleras" situadas en los faldeos de las Sierras Chicas, uno de los escenarios de mayor riqueza paisajística de la región metropolitana.

En su origen como pueblo industrial, la explotación de la cal se constituyó en la fuente de desarrollo local, apoyada por la presencia del ferrocarril Mitre, que vinculaba la cantera con el pueblo y la ciudad de Córdoba. Con el correr de los años, la explotación de las canteras se intensifica, el ferrocarril se extiende y el impacto ambiental de las actividades industriales va deteriorando el paisaje progresivamente, marcando un irreversible perjuicio ecológico y ambiental, con la consecuente pérdida de la calidad de vida de la población.

Resulta interesante subrayar el patrimonio religioso que caracteriza al área, incluyendo templos y capillas. Por su valor arquitectónico particular, se destaca, entre otras, la iglesia de Nuestra Señora de Nieva, del reconocido arquitecto cordobés Jaime Roca. También es de gran valor la presencia de vestigios de la actividad económica esencial que identifica a la localidad, como los viejos hornos, 


\footnotetext{
${ }^{3}$ Extraído del Convenio

Específico de Asesoramiento

y Asistencia Técnica entre

la UNC, FAUD y equipo

del Instituto del Color que

desarrolla el proyecto,

compuesto por las arquitectas

María Marta Mariconde,

Adriana Incatasciato y María

Inés Girelli, y la munici-

palidad de Malagueño.
}

los secaderos de piedras, las huellas de los viejos caminos y el ramal del ferrocarril. Allí se instalaron las familias de los trabajadores de esta actividad a principios del siglo XX, con tipologías de viviendas modestas, algunas italianizantes, de influencias racionalistas y morfologías sencillas, conformando sintaxis parciales o puntuales de valor arquitectónico.

Malagueño ha ido sufriendo las consecuencias problemáticas de los procesos de especulación inmobiliaria, que afectan en mayor o menor medida a numerosos municipios del área metropolitana de Córdoba, enfatizándose últimamente la presencia de gran cantidad de asentamientos de barrios privados y countries dentro de ejido municipal.

En el año 2008, uno de los equipos de investigación del Instituto del Color de la FAUD UNC accedió al ámbito de la gestión municipal de la localidad. El municipio, ya alertado de la situación de la localidad y su deterioro previsible, estaba interesado en estudios y planteos de intervención urbana. Desde este instituto de la FAUD UNC se intentó transmitir al intendente y a las autoridades, en un prolongado proceso de diálogo, la imperiosa necesidad de tomar conciencia acerca de la pérdida de la identidad de Malagueño, ofreciendo una propuesta de factibilidad para revalorizar su imagen de pueblo de viviendas modestas y de atmósfera sosegada y tranquila. Esta propuesta se evidenciaba, casi a la luz de todos sus habitantes, a partir de las excelentes posibilidades de recuperar micro-áreas urbanas que por su valor significativo, por su expresión morfológica, su patrimonio histórico y sus potencialidades paisajísticas y ambientales, podían ser reinsertadas en el imaginario social de la región.

Desde la especificidad de la morfología urbana, y con este fin, se estudiaron acciones de uso del recurso cromático como una de las estrategias más efectivas y económicas para revalorizar la localidad y reposicionarla en la región.

Es así que, a fines del 2010, se gestionó la firma de un convenio específico de asesoramiento y asistencia técnica entre la UNC, FAUD y el equipo del Instituto del Color, y la municipalidad de Malagueño, con el objeto, sin dudas, de que esta acción provocara la sinergia necesaria para repensar la planificación urbano-regional, promoviendo una profunda innovación con respuestas ambientalmente adecuadas y sostenibles, y con oportunidades equitativas para la sociedad ${ }^{3}$. 
Las acciones se afirmaron en el marco de una planificación integral, contemplando criterios de ordenamiento territorial ambiental de la localidad y sus territorios vecinos, con un equipo técnico, interdisciplinario y de consenso, que contó entre los distintos actores intervinientes con las profesionales impulsoras y desarrolladoras de la propuesta, autoridades de la gestión municipal, técnicos, empresarios y vecinos.

La propuesta se focaliza en la intensificación del sistema de lugares existente, emergente de la misma traza fundacional de la localidad; tales lugares fueron detectados en la fragilidad de su lectura por las integrantes del equipo. El énfasis por ganar su expresión o presencia se lograría a través del proyecto de diseño cromático de rescatar expresas fachadas de interés, de valor histórico y de patrimonio modesto. Las mismas aparecerían dentro del recorrido, aisladas o en sintaxis parciales, y reveladas con cierto criterio de intervención cromática que le permitiría al habitante una clara lectura sintáctica, ya sea en su habitual recorrido a pie, en bicicleta o automóvil.

En la propuesta de intervención también se consideraron criterios generales para la organización y sistematización de los componentes del lenguaje urbano, algunos existentes y de distintas expresiones formales, otros obviados y necesarios en su uso. Esto para permitir la rápida concreción y la gradual recuperación de la imagen urbana, conformando en el imaginario colectivo una aprehensión de un sistema de lugares memorable.

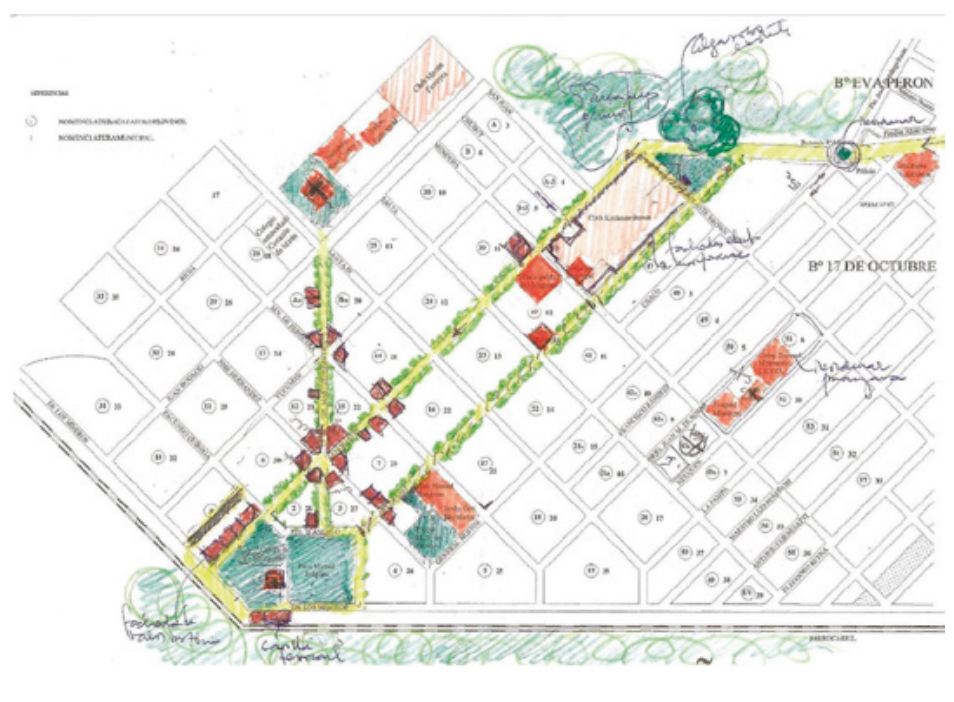

Figura 1. Planimetría general de la propuesta. 
El proyecto fue propuesto en etapas, coordinadas por la municipalidad. Sería acompañado paulatinamente por la construcción de la arista social, con una consecuente concientización colectiva de la comunidad, a partir de la amplia participación de distintos actores sociales voluntarios y la presencia de la Fundación Minetti como motora de esta acción.

\section{Propuesta de diseño cromático}

El criterio adoptado para el diseño cromático se limitó a que el color debía actuar como un fuerte instrumento que estructurara y organizara las imágenes dentro del sistema de lugares detectado, dada las cualidades perceptivas de las fachadas de interés, referenciando así una correcta y clara orientación para el habitante.

La intervención cromática apuntaría a revalorizar el enlace de ciertos fragmentos de una cuadra, la definición de determinadas esquinas de valor patrimonial, jerarquizar direcciones o marcar puertas o pausas en un recorrido que, junto a otros componentes del entorno urbano, posibilitarían construir el significado de una imagen ambiental fuerte y eficiente. Cada fachada debería tener valor por sí misma y en sintaxis debería ser legible y comunicable, permitiendo la construcción de mapas cognitivos y estableciendo identidad en el recorrido.

Se estudiaron los detalles de sus planos envolventes, detectando la estructura de sus partes, la relación de llenos y vacíos, presencia de basamentos, cornisas, ornamentaciones, etc., que facilitaran definir y adoptar un criterio de diseño coherente en los arreglos cromáticos, definiendo una lectura de volumen equilibrado en su expresión.

Para ello se adoptaron posiciones teóricas en lo relacionado al color, y particularmente al color urbano, de un claro posicionamiento del equipo en la temática, y que estuvieron siempre presentes desde la gesta de la propuesta. Tales posturas legitimarían la actuación del color en las fachadas, la aplicación de los contrastes cuantitativos o de superficie, y la ley de Kircher (dos tonos entablan mejor relación cuando hay un salto grande en alguna de las tres variables, preferentemente en valor). De esta manera la propuesta contribuiría a un adecuado "confort visual", de buena imagen o equilibrio visual. 
La paleta se centró en la utilización de un sistema policromático de tonos cálidos, a partir de arreglos por contrastes de armónicos.

Las mayores superficies de los planos envolventes se trabajaron predominantemente sobre la base de terciarios terrosos, pardos rojizos y ocres amarillentos, con claves de valor medias y medias-altas, contrastando con tonos grises azuladosverdosos para el tratamiento de aberturas, en clave de valor bajo.

Los basamentos, detalles de ornamentaciones y coronamientos se definieron, con saltos de valor, a partir de los utilizados en los muros bases y según su ubicación, particularmente en función de la sintaxis parcial o general de la cuadra.
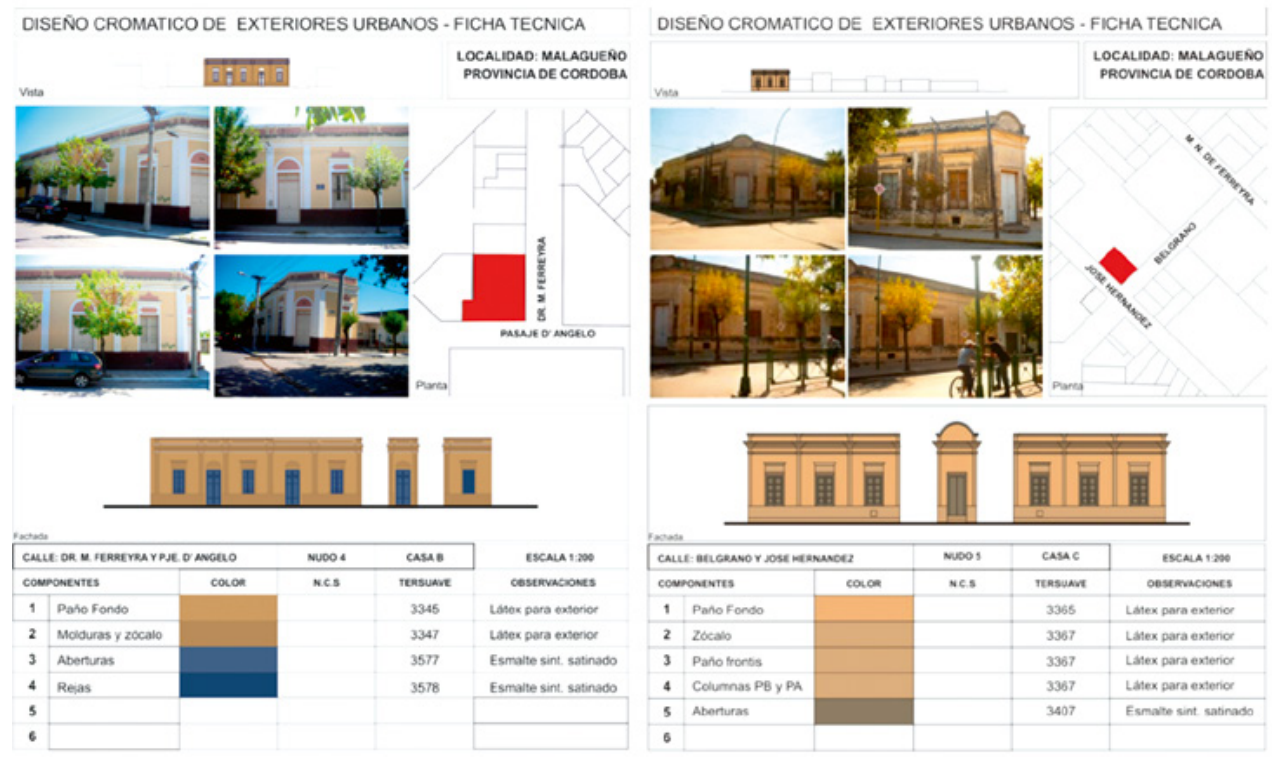

Figura 2. Fichas técnicas. Fuente: autor. 
Desde 2010, esta propuesta de revalorización quedó dormida en el expediente, por motivos desconocidos, y que suponemos derivados de la propia gestión del gobierno municipal para dar prioridad a otros intereses, o de vislumbrar una viabilización económico-financiera para su concretización. La plaza principal fue remodelada años atrás, adoptando algunos de los criterios generales sugeridos en la propuesta.

A comienzo del 2019 se nos notificó informalmente de la iniciación de obras en la remodelación del antiguo edificio de bomberos, frente a la plaza principal, inaugurado como la sede del nuevo Registro Civil, utilizando en sus fachadas la propuesta cromática presentada.

Como equipo, nos queda la satisfacción de haber logrado la concientización y el reconocimiento de las autoridades de gobierno, y de distintos actores de la comunidad, más allá de la concreción de la propuesta. Vislumbramos la necesidad de vínculos, de diálogo y trabajo entre la universidad y la comunidad, a la vez de haber adquirido la confianza de nuestra actuación para construir, en un camino lento pero seguro, la sustentabilidad ambiental-paisajística.

De todas maneras, consideramos indispensable una fuerte actitud y voluntad política para activar la sinergia entre quienes avalaron la propuesta en la comunidad; el no crear posibilidades y abrir puertas impide continuar el camino emprendido.

\section{Caso Huerta Grande}

El crecimiento descontrolado en muchas localidades serranas de carácter turístico, en el corredor del valle de Punilla, está evidenciado por el éxodo de habitantes de la ciudad capital, quienes adquieren inmuebles como vivienda permanente. Este fenómeno está causando, en determinados casos, alteraciones evidentes, y en otros, deterioro en el tejido y en el patrimonio cultural y ambiental de la región. Y si no se toman las medidas necesarias para frenar la situación, redunda en riesgos de aumento.

La ausencia de una lógica de desarrollo urbanístico racional y paulatino, que debiera ser propia de una localidad turística, trae aparejados problemas en su funcionamiento como sistema urbano, y en la imagen total de la ciudad, comprometiendo su paisaje. A esto se suma la especulación inmobiliaria, la cual induce tanto a grupos de inversores como a vecinos a acciones individuales, no concertadas. 
Dichas apreciaciones no exceptúan a ciertas localidades del valle de Punilla, corredor de crecimiento pujante y sostenido, posicionado como una de las principales sedes turísticas del país. Esas localidades tienen gran carácter de interés, en distintos aspectos, por sus tipologías arquitectónicas de valor histórico, por sus reservas ambientales, por sus paisajes naturales y por sus ofertas culturales a la comunidad, entre otras.

Huerta Grande se halla ubicado aproximadamente a 75 kilómetros de la ciudad de Córdoba, en el centro del valle de Punilla, accediendo por la ruta nacional 38. Adosado a sus vecinas localidades de Villa Giardino y La Falda, forma parte del aglomerado urbano lineal que discurre a lo largo del valle.

Está asentado sobre un territorio de marcadas topografías, desde suaves ondulaciones hasta la abrupta y asimétrica sierra, la cual de a poco se transforma en el cordón de las Sierras Chicas, al oeste de la provincia.

El nombre de Huerta Grande se debe a la fertilidad de sus tierras, muy ricas en humus, elemento que favoreció el desarrollo de numerosas huertas en la zona.

El municipio fue fundado oficialmente el 3 de enero de 1941. Actualmente cuenta con 6000 habitantes estables, y se ha transformado en punto de atracción turística, como casi todas las localidades del valle de Punilla.

Desde entonces se han ido instalando numerosas colonias de vacaciones y hoteles de importantes gremios nacionales, con la inquietud desde el gobierno municipal por mantener el perfil de localidad turística rural, preocupándose por la conservación del medio ambiente en su estado natural, y una completa gama de servicios para el turismo social.

Ante esta perspectiva de situación, y al igual que el caso de la localidad anterior presentada, es de necesidad contar con instrumentos de ordenamiento normativo para que, desde la gestión del gobierno municipal, se impidan distorsiones, alteraciones o desapariciones de aquellos valores o potencialidades con los que cuenta la localidad. 
${ }^{4}$ Antecede el proyecto de investigación de la Arq. María Marta Mariconde como becaria de la agencia Córdoba Ciencia, de la provincia de Córdoba, período 1999-2000. El tema fue: “La gestión ambiental urbana. Aplicación en la localidad de Huerta Grande, Córdoba" y luego continúa como proyecto de investigación con aval de la SECyT UNC, dirigido por la Arq. María del Carmen Franchello, en el periodo 2000-2001, con el tema: "Huerta Grande: Proyecto patrimonio".
Entre los años 2000-2001, en el marco de un proyecto de investigación ${ }^{4}$, se realizó un estudio de la localidad, enfocado a detectar, relevar y sistematizar, en un fichado, a aquellas construcciones de valor patrimonial que colaboraban en la imagen del paisaje de la localidad. El patrimonio arquitectónico se reconoció en dos instancias diferentes: el centro urbano, caracterizado por un desarrollo lineal materializado por un canal sinuoso, cuyas envolventes predominantemente se expresan en lenguaje neocolonial, constituyendo un rasgo característico de la villa serrana; y la localización de una serie de hoteles y viviendas pintorescas, residencias de turismo estacional a lo largo del eje de la calle principal del pueblo y distribuidas en barrios tradicionales, que se constituyen en elementos arquitectónicos de acentuado valor patrimonial y paisajístico.

En el primer caso, el centro urbano se conforma por una sucesión de comercios de una sola planta, o comercios en planta baja y vivienda en planta alta, correspondientes a las décadas de los treinta, cuarenta y cincuenta, con tipologías expresadas en lenguaje predominantemente neocolonial, a las que le provocaron mutaciones que se evidencian en las envolventes, aun cuando se haya conservado el esquema tipológico original. Este sector tiene características singulares, que se expresan especialmente en las esquinas, con ochavas jerarquizadas por coronamientos mixtilíneos. De esta manera se enlazan los distintos tramos sucesivos de comercios, conformando una imagen continua de escala homogénea que constituye rasgos de permanencia identificatorios de la localidad.

Si bien existe un código de edificación en la municipalidad de Huerta Grande, la ausencia de normativa específica acerca del patrimonio arquitectónico ha posibilitado intervenciones desatinadas con respecto a los valores patrimoniales detectados en el centro como conjunto, referidos a la armonía que determina su escala homogénea y su lenguaje, aun cuando se trate de arquitectura de rasgos modestos. 
Desde el Instituto del Color, consideramos que aquel proyecto constituye un instrumento urbanístico de gran valor, para rescatar y revalorizar bienes culturales, históricos y arquitectónicos, en sectores o áreas paradigmáticas de la villa serrana. Esto implicaría un escenario urbano claramente legible, vivencialmente identificable y memorable para sus habitantes y los turistas que la visitan.

Sin embargo, las autoridades de la gestión no apoyaron este proyecto, quizás por ausencia de concientización temática, de actitud o voluntad política, o deficiencia de recursos económicos, por lo que esta propuesta de trabajo quedó archivada.

Hace un par de años, con renovación de gente joven y dinámica en la gestión municipal, se restablecieron los vínculos institucionales de la FAUD. Se convocó así al Instituto del Color, atendiendo a su trayectoria, para conocer acerca de sus acciones y actividades en la ciudad, en especial a lo que refiere a la revalorización de la imagen del espacio público a través del diseño cromático.

Se llegó al acuerdo con el intendente de trabajar en el área central de la localidad serrana, definida por el eje de la avenida San Martín, desde la plazoleta El Cóndor, que marca el ingreso a la villa serrana por la ruta nacional 38, hasta la calle La Rioja, esquina de la terminal de ómnibus, consolidando un área variada en cuanto a sus usos, de carácter residencial, de servicios y comercial de uso diario. En la misma se asientan ciertas tipologías arquitectónicas de valor morfológico expresivo o significativo, histórico, algo desvalorizadas, y otras más modestas que, por su asentamiento sobre dominantes pendientes, por momentos se evidencian interrumpiendo la continuidad espacial.

Se detectaron como prioritarias acciones de revalorización de la imagen, reforzando el carácter de interés como conjunto, como sintaxis, rescatando las tipologías con mayor valor patrimonial e incorporándolas con propuestas de nuevos usos. En este punto es donde se explicita al intendente la existencia y el valor del trabajo realizado como proyecto en el año 2000 para la detección de inmuebles de valor histórico-patrimonial. 
En este marco, la municipalidad de Huerta Grande está trabajando en la planificación de su territorio contemplando estas intenciones, y encarando otras acciones prioritarias, con instrumentos normativos que aporten a la consolidación de la imagen, como es el caso del arbolado público, mobiliario urbano, publicidad y espacios verdes.

Los miembros del Instituto han manifestado su actitud y voluntad de intervenir en la localidad, acompañando a la gestión de gobierno, aportando saberes que le competen como centro de investigación.

En este marco de consenso, el intendente de la localidad y el decano de la FAUD UNC firmaron una carta de intención, manifestando su acuerdo para establecer relaciones que promuevan el desarrollo de actividades de interés para ambas instituciones, con el objetivo de gestionar la suscripción de un convenio específico de asesoramiento y asistencia técnica para concretar tareas de revalorización de la imagen, con propuestas de proyecto cromático.

Se definió una intervención puntualizada, en dos etapas de concreción, con un proyecto cromático que abarca las fachadas de la avenida San Martín, eje del centro de la localidad, desde la plazoleta El Cóndor hasta la calle La Rioja, esquina de la terminal de ómnibus. 


\section{Propuesta cromática ${ }^{5}$}

Para la primera etapa de este proyecto cromático, y con la intención de una intervención ágil, abierta y flexible en el área, se propuso como primera medida diseñar una carta cromática. La misma se justificó con una paleta de colores basada en el rescate de la esencia comercial y turística del sector, con la diversidad de la imagen patrimonial de conjunto del eje central, y con la impronta de tranquilidad que respira esta localidad serrana de carácter turístico rural.
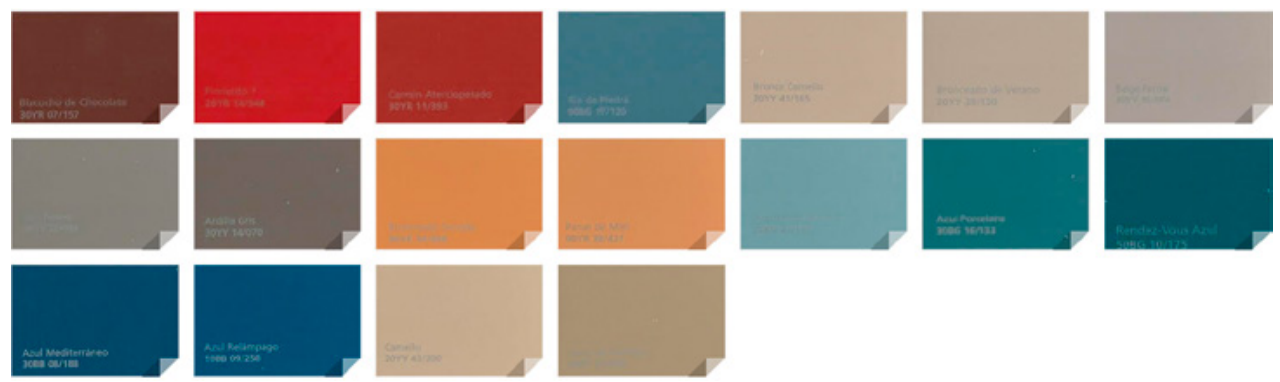
La carta fue pensada como una propuesta normativa de paleta policromática por grupos de armónicos contrastantes entre sí, de tonos terrosos, ocres y terracotas, y azules verdosos y neutros. Se presenta como un catálogo de colores posibles, factible de convertirse en ordenanza que pueda ser utilizada en el tiempo, mientras la municipalidad avanza paralelamente, organizando las acciones necesarias para la revalorización del área, tales como la planificación de nuevos solados para las veredas, ordenamiento de arbolado público, señalética, cartelería publicitaria y mobiliario. Esta carta utiliza arreglos equilibrados, a través del uso de tonos, valores y saturaciones que fortalezcan la imagen, estableciendo un concepto de confort visual en su aprehensión total. El color debiera emerger como estructurador del espacio, calificando un recorrido claro y comprensible, salvando la dificultad de su lectura actual.

El criterio de aplicación se estudió en propuestas de sintaxis totales, parciales o puntuales, sobre tipologías de interés morfológico e histórico, de situación en el tejido, o de usos, en puntos estratégicos o en nodos de interés, que en el recorrido admitan la policromía con distintas posibilidades de arreglos cromáticos.

De esta manera, definidos los criterios y una normativa de paleta policromática de tonos codificados, en el momento de cada intervención de fachadas sería posible elegir los colores del catálogo normativo.

El área se pensó como integrante de un sistema de lugares a escala de toda la localidad, vinculando los referentes principales, como hoteles, lugares recreativos, paseos, puntos panorámicos, logrando una lectura de unidad clara por parte de sus habitantes y de los turistas.

En esta primera etapa, la propuesta cromática se centró en las fachadas envolventes de la avenida San Martín, en el tramo principal de la actividad comercial y con presencia de tipologías arquitectónicas de mayor interés patrimonial, comprendido entre las calles Hipólito Yrigoyen y Córdoba.

Las tareas previas al proyecto a realizar por parte del Instituto incluían la presentación oral y gráfica ante autoridades, público en general y vecinos de la localidad, exponiendo sus trabajos de intervención cromáticas en casos testigos desarrollados previamente en localidades del valle de Punilla con la manifiesta intención de trabajar en propuestas cromáticas, de manera articulada con la municipalidad y con los actores sociales de la comunidad y las empresas locales que demostraran iniciativa de hacerlo. 
Para el desarrollo de la propuesta se consideró necesario el recorrido del sector, con exhaustivo relevamiento fotográfico del eje, desde ambas veredas, como importante material de trabajo que luego debía ser compaginado y verificado sobre documentación catastral municipal.

Como documentación gráfica, fue indispensable concretar una planimetríaaerofotometría del área general, abarcando el eje de avenida San Martín desde la plazoleta El Cóndor hasta la calle La Rioja, esquina de la terminal de ómnibus local, que se presentaría luego a la municipalidad para visualización del público en general.

La organización y sistematización de fachadas por sectores para la individualización operativa en su ejecución se desarrolló con un fichado técnico de cada una de las fachadas frentistas, con propuesta de color y especificación de los códigos de pintura, según catálogo normativo propuesto con sistema de notación NCS (Natural Color System).

El catálogo de pintura sería adaptado según la empresa de pintura que interviniera oportunamente en su ejecución.

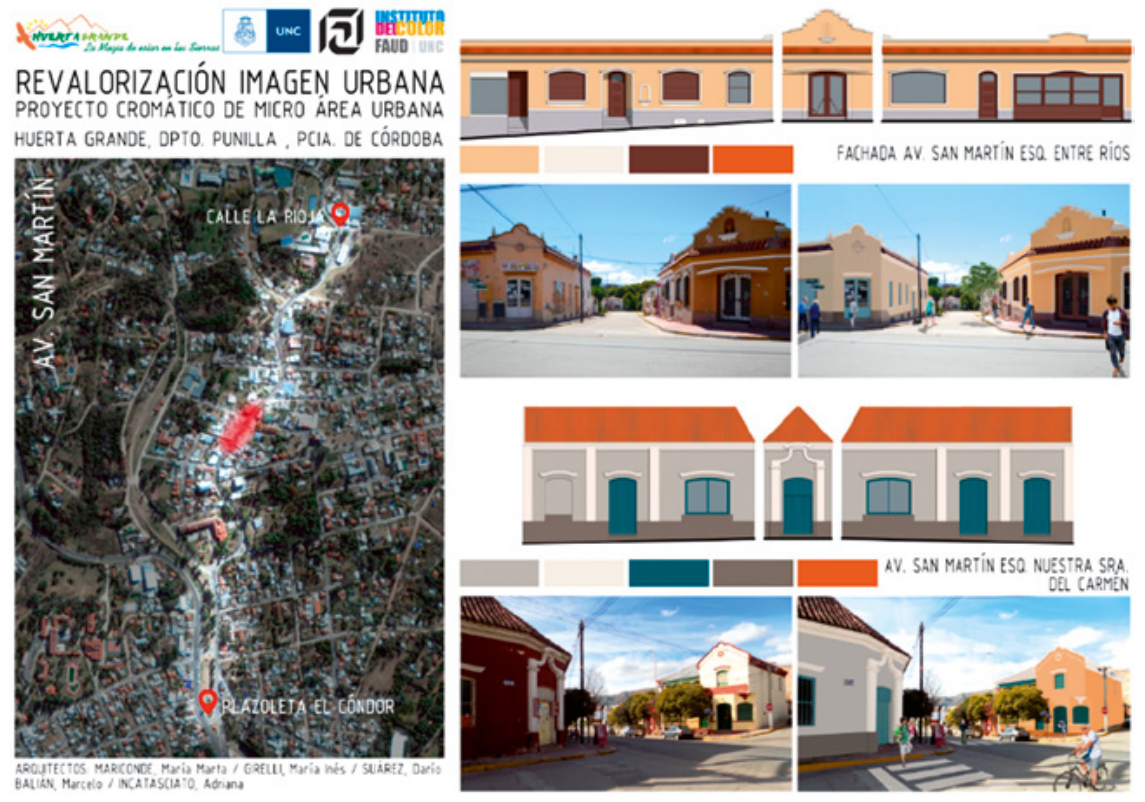

Figura 4. Panel presentación de la propuesta. 


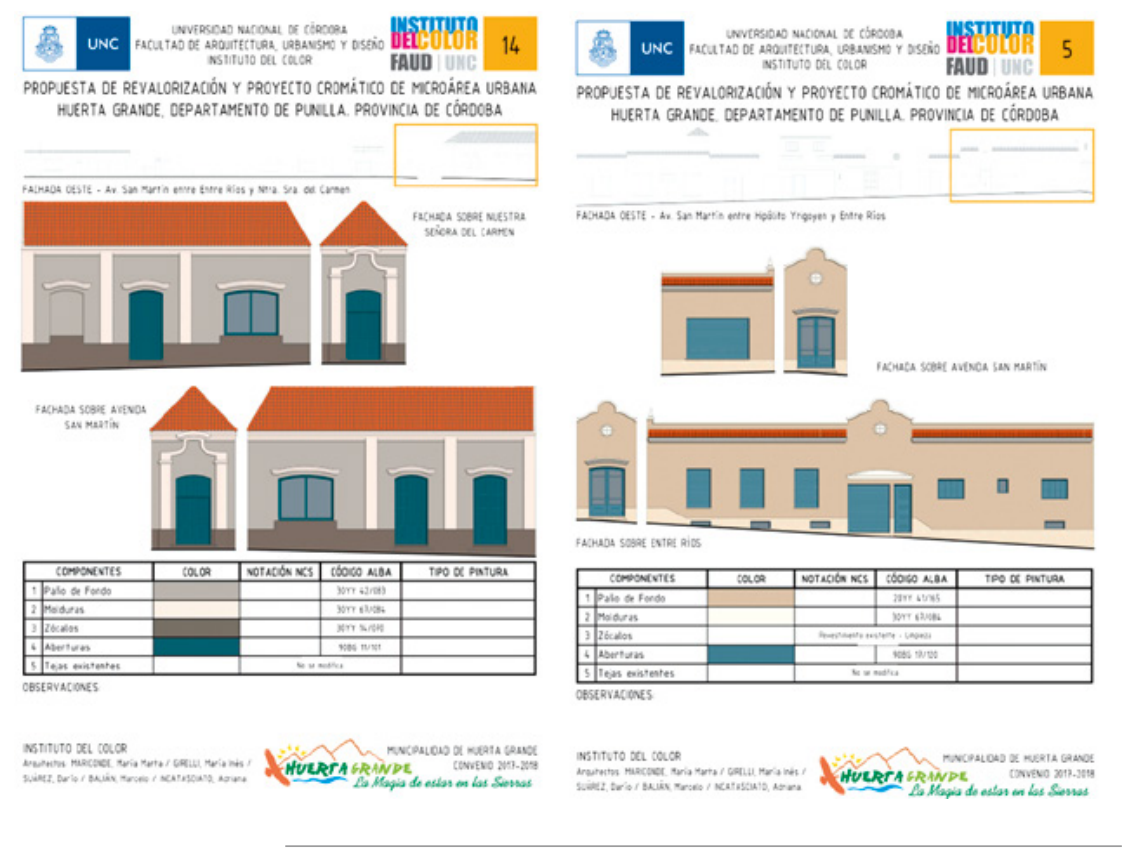

Figura 5. Fichas cromáticas por fachadas.

Fuente: autor.

La expresión formal deseada quedaría denotada a través de enfoques fotográficos, con lectura de sistemas cromáticos existentes y con propuestas según proyecto cromático.

Simultáneamente, el Instituto del Color quedó encargado de definir las estrategias de gestión, en consenso con la municipalidad, intermediando entre las empresas de pintura y la municipalidad, además de la confección del Convenio específico entre el Instituto del Color, FAUD UNC y la municipalidad de Huerta Grande.

\section{Consideraciones de la revitalización de Huerta Grande}

El trabajo está a la expectativa de que el gobierno municipal decida concretar esta propuesta. Se entiende que se manejan tiempos diferentes desde la gestión, atentos a requerimientos de los proyectos emergentes y de las prioridades respecto a distintas necesidades en distintos aspectos de la población. 


\section{CONCLUSIONES}

Reafirmamos que, a partir de pensar con una actitud consciente y reflexiva, desde operaciones-acciones locales en las que deben indefectiblemente actuar en consenso y alianza el gobierno, las organizaciones intermedias y la Universidad, es posible "rearraigar lo desarraigado."

Se debe trabajar en la consolidación de la identidad a partir de recuperar a la población, particularmente familias en edad productiva, a la vez que operar sobre el soporte físico en tareas de revalorización del tejido existente. Esta ecuación logra la puesta en valor del patrimonio vivo, arquitectónico y social, y técnicamente se puede llevar a cabo con los distintos actores sociales de una comunidad.

Los espacios físicos de la ciudad que son apropiados o aprehendidos por sus habitantes son, ante todo, reflejos de los imaginarios colectivos. La construcción y apropiación de los lugares responden a la idea de espacios donde puede leerse la identidad, la historia y la relación individuo-soporte físico.

El equipo de trabajo, en función de las experiencias de intervenciones cromáticas concretadas a lo largo de su trayectoria, ha podido ampliamente verificar que el color es considerado como una de las herramientas más fuertes y efectivas, de alto valor y dinamismo en el cambio de la imagen, a la vez que relativamente económica para la revalorización de micro-áreas urbanas ilegibles o deprimidas. Esta herramienta, aplicada tanto en tipologías arquitectónicas de interés como en sintaxis urbanas parciales o totales, aporta una clara lectura sintáctica, conformando en el imaginario colectivo un sistema de lugares memorables.

Y por último, nos interesa aclarar que es el Estado quien tiene la responsabilidad de argumentar y arbitrar las acciones para lograr una mejor calidad de vida para los habitantes. De esta manera se podrá afianzar el "pertenecer", el "arraigarse", que permite fortalecer el sentido de identidad de una ciudad, haciéndola única, irrepetible y memorable. 


\section{REFERENCIAS BIBLIOGRÁFICAS}

Améndola, Giandoménico (1997). La cittá postmoderna. Magie e paure della metropoli contemporanea. Roma: Laterza \& Figli Spa (Traducción castellana por Marisa García Vergaray y Paolo Sustersic. España: Fareso S.A., 2000).

Curtit, Guillermo (2003). Ciudad, gestión local y nuevos desafíos ambientales [CIAM, Centro de investigaciones ambientales]. Buenos Aires: Espacio.

De Schiller, Silvia (2001). Sustentabilidad y transformación del tejido urbano en la cuadrícula latinoamericana. En Ana Falú y Marisa Carmona (eds.) Globalización, forma urbana y gobernabilidad (pp. 187-196). Argentina: SECyT UNC.

Del Acebo Ibáñez, Enrique (1996). Sociología del arraigo. Una lectura crítica de la teoría de la ciudad. Buenos Aires: Editorial Claridad.

Mariconde, María Marta (2000). La revitalización urbana y las prácticas sociales. Revista del Centro Marina Waisman de Formación de Investigadores en Historia y Crítica de la Arquitectura, (3), pp. 32-37.

Sánchez, L., y Cuezzo, María Laura (2012) Reflexiones sobre el concepto patrimonial modesto. Estudio de caso: las ciudades de Mar del Plata y San Miguel de Tucumán. En: Daniela Moreno y Ana Lía Chiarello (comps.) Cuadernos de Historia Urbana (pp. 254-267). San Miguel de Tucumán: Universidad Nacional de Tucumán, Facultad de Arquitectura y Urbanismo.

Sanz, Juan Carlos (1993). El libro del color. Madrid: Ed. Alianza.

Villafañe, Justo (1996). Introducción a la teoría de la imagen. Madrid: Pirámide.

Waisman, Marina (1994). La arquitectura descentrada. Bogotá: Escala.

(1989) “El patrimonio modesto y su reutilización”. Revista Summa, № 266-67

(1995). El patrimonio modesto. Umbrales, Crónicas de fin de siglo. Revista del CISPREN, 3 (p. 4). 